Original Research

\title{
The Effect of Management Regime on Airborne Respirable Dust Concentrations in Two Different Types of Horse Stable Design
}

\author{
Emma-Jane Auger, Meriel Jean Scott Moore-Colyer* \\ School of Equine Management and Science, Royal Agricultural University, Cirencester, Gloucestershire, UK
}

\section{A R T I C L E I N F O}

\section{Article history:}

Received 27 September 2016

Received in revised form 15 December 2016

Accepted 16 December 2016

Available online 23 December 2016

\section{Keywords:}

Dust

Respirable

Stable

Equine asthma

\begin{abstract}
A B S T R A C T
Airborne respirable dust (ARD) $(<5 \mu \mathrm{m})$ in the stable environment is strongly implicated in equine asthma. Bedding, forage, ventilation rate, and stable management activities all contribute to ARD. This study investigated the relationship between ARD in the breathing zone (BZ) and the stable zone (SZ) in eight American barns (ABs) and eight stable complexes with individual stables under four different management regimes. Airborne respirable dust was measured in eight replicate stables per regime in $\mathrm{ABs}(\mathrm{n}=32)$ and eight per regime in single stables $(\mathrm{n}=32$ ). Regimes were as follows: (1) steamed hay and shavings; (2) dry hay and shavings; (3) haylage and straw; and (4) dry hay and straw. Samples were taken in quite periods between 3 PM and 4 PM hours. Airborne respirable dust levels were analyzed using Split-Plot analysis of variance and Wilcoxon matched-pairs test (Genstat 15) with $P<.05$ as significant. The lowest ARD ( $<360 \mathrm{RP} / \mathrm{L}$ air) was found for shavings and steamed hay in $\mathrm{AB}$ and single stables in both BZ and SZ. Straw and dry hay in ABs produced ARD of 6,250 (SZ), 5,079 RP/L air (BZ) which was greater $(P<.05)$ than the 2,901 (SZ) and 942 (BZ) RP/L air in single stables. Straw and haylage produced more ARD across both zones in single stables compared with ABs. Shavings and dry hay $=$ more dust in the BZ than in the SZ, whereas straw and haylage = higher ARD in the SZ versus the BZ across both stable designs. Using dry hay and/or straw cannot be recommended as a suitable management regime for stabled horses.
\end{abstract}

(c) 2016 Elsevier Inc. All rights reserved.

\section{Introduction}

It is widely acknowledged that airborne respirable dust (ARD) of $<5 \mu \mathrm{m}$ in size found in the stable environment has a major negative impact on respiratory health in horses and can cause the debilitating allergic condition known as equine asthma [1-5]. The economic impact of respiratory problems in racehorses can be considerable and are linked to poor performance in young Thoroughbreds [6].

\footnotetext{
* Corresponding author at: Meriel Jean Scott Moore-Colyer, Royal Agricultural University, Stroud Road, Cirencester, Gloucestershire GL7 6JS, UK.

E-mail address: meriel.moore-colyer@rau.ac.uk (M.J.S. Moore-Colyer).
}

Respiratory problems as a whole are the second biggest cause of days lost to training in the Thoroughbred industry $[7,8]$.

Airborne dust in the stable environment is composed of different sized particles of plant fragments, mites, bacteria and mould spores, yeasts, and endotoxins [9] with the level and composition being influenced by the choice of bedding [10], forage [11], and horse care activities, such as mucking out and sweeping [12]. The persistence of dust in the air and the probability of inhalation by the horse into the different regions of the respiratory tract are influenced by release rate from bedding and forage, particle size [13], and the speed of removal by ventilation rate which can vary greatly between stables $[14,15]$. In humans, dust entering 
the nose and throat (inhalable dust) is composed of particles of $<100 \mu \mathrm{m}$, the extrathoracic portion that reaches the larynx is $10-100 \mu \mathrm{m}$, whereas tracheobronchial fraction (potentially caught on the mucociliary boarder) is $10 \mu \mathrm{m}$ [16], although May et al [17] have suggested that a small percentage of these particles can reach the lower airways. However, it is widely accepted that the potentially allergenic dust to horses, which can reach the noncilia protected alveoli, is similar to in humans at $<5 \mu \mathrm{m}$ in size $[13,18,19]$ and includes some of the fungal spores, notably Aspergillus spp $(2-4 \mu \mathrm{m})$ which are of optimal size for alveolar deposition. Thermophilic actinomycetes such as Thermoactinomyces vulgaris and Saccharopolyspora rectivirgula are small enough at $<1 \mu \mathrm{m}$ to flow freely with inspired and expired air, but repeated exposure increases the chances of particles being caught in the alveoli and so these actinomycetes are also implicated in the allergic respiratory disorder equine asthma [20].

Airborne particles obey Stokes Law [21] and sediment at velocities proportional to the square of their radii, and this can result in particles remaining in the air for extended periods, increasing the likelihood of inspiration by the horse. The best way of reducing the animal: dust interaction when horses are housed is to ensure adequate ventilation and to reduce contamination of the air from sources such as bedding and forage.

Many horses are now kept in loose boxes within an American barn (AB) system and thus share airspace. Jones et al [22] reported serious negative consequences in terms of respiratory health, when seven horses shared airspace of approx. $39 \mathrm{~m}^{2}$, particularly during calm conditions when the ventilation rate was low at only 6.6 changes of air/hr. Increasing the ventilation rate in an $A B$ system by leaving windows and doors open was reported [23] to significantly decrease particulate matter in the air; however, horse owners often cite inclement weather as a reason for closing doors and windows. Art et al [13] suggested that the benefits of a low-dust regime in one stable can be lost; unless, the adjacent stables are also on lowdust regimes and this cross-contamination could be more problematic if ventilation rate is compromised by closing windows and doors.

In single stables, commonly $3.6 \times 4.2 \mathrm{~m}$, the airspace available to the horse is restricted by roof height, and air movement can be negligible particularly if back or side windows are kept closed. However, the horse only inhales dust created from its own bedding and forage and does not have to be subjected to the dust created from neighboring stables or from horse management activities such as yardsweeping, filling hay nets, and grooming, which can negatively impact on animals in ABs.

Previous work [17] has shown that time of day, stable construction, and ventilation can influence ARD in the general stable zone (SZ) in TB stables. However, the study did not compare the effect that different types of bedding and forage can have on the dust levels in the breathing zone (BZ), compared with the SZ in different stable designs.

The aim of this study was to investigate the contribution of bedding and forage on ARD in the BZ and general SZ when horses were kept on different management regimes. The contribution of different management regimes to ARD within single stables or when sharing air space as in an $A B$ was also determined with the objective of identifying suitable management regimes for each housing system.

\section{Methodology}

\subsection{Experimental Design}

A split-block design study was carried out in order to measure the ARD produced in ABs compared with single stable complexes. Four different management regimes were employed with two replicate barns and single stable complexes per management regime. Dust samples (2) were collected from the BZ and SZ from four replicate stables per barn/complex (16)/management regime (4) were collected. Within the randomized split-block design, stable type was designated as whole plots, zone as subplots, and management regime as treatments thus $\mathrm{n}=128$.

\subsection{Stables and Management Regime}

Thirty-two individual stables in $8 \mathrm{AB}$ and 32 individual stables in 8 straight block stables (SS) across Gloucestershire, Wiltshire, and Berkshire in the UK were sampled for ARD concentrations during November and December in 2013. American barns were all new construction with walls of breeze-blocks and wooden slats and corrugated iron roofs. Divisions were wooden bottom and bar top partitions dividing the $12 \times 12$ or $12 \times 14$-ft stables. All buildings had open windows along one side, roof ventilation, and large open end doors; thus, ventilation was good. Barns were of different sizes and ranged from 7 to 22 individual stables under one roof. Within each barn, all horses were kept on the same management regime.

In single stable complexes, individual stables were $12 \times$ $12 \mathrm{ft}$ and were either stone or brick construction with either tiled or slate roofs. All stables had half-doors open to the outside air and windows in the side or back although these were of varying size and sometimes kept closed. All straight stable had half-doors open to the outside, and all but two had windows or vents in another wall.

Samples were taken during quiet periods between $3 \mathrm{PM}$ and 4 PM when all activities such as mucking out, riding, grooming, and yard sweeping had been completed in the morning. During sampling, all horses were present in their boxes and feeding on forage that had been placed into their boxes at the end of the morning activities. Sampling during quiet periods was undertaken in order to reduce sampling of environmental dust created by management activities such as grooming, mucking out, filling hay nets, and yard sweeping. Quiet period sampling therefore maximized the chance of measuring dust from forage and bedding in the BZ and SZ.

The four management regimes investigated were as follows: (1) steamed hay and shavings; (2) dry hay and shavings; (3) haylage and straw; and (4) dry hay and straw. Eight replicate stables per regime per housing system were sampled twice, once in the horse's BZ and once in the general SZ. Management of all types of bedding consisted of daily removal of feces and soiled bedding; thus, the beds 
were partially turned over, and small amounts of fresh bedding were added when needed.

\subsection{Dust Sampling}

Dust samples were taken from two areas within each stable: (1) from the area close to the horse's nose (BZ) as it fed and (2) the middle of the stable (SZ) using a cyclone personal air sampler (Munro personal sampler AS 200) set to sample $1.9 \mathrm{~L}$ of air per minute. Each zone was sampled for 3 minutes, and $5.7 \mathrm{~L}$ of air was sampled. In order to sample the BZ, the cyclone sampler was attached to one side of the horse's head collar, close to the nose, and attached via a 1-meter plastic tube to a pump which was attached to a girth roller, so the horse could move its head freely during the sampling period. The SZ sample was taken by holding the cyclone sampler $3.6 \mathrm{ft}$ off the ground in the middle of the stable and allowing the pump to run for 3 minutes. The horse was free to move around the stable when SZ samples were taken.

The cassettes of the cyclone sampler were preloaded with nitrocellulose filter papers in dust-free conditions in the laboratory prior to visiting the stables. The cyclone pump was set to flow at $1.9 \mathrm{~L}$ of air/min in order to facilitate the separation of dust by size. Airborne respirable dust, those $<5 \mu \mathrm{m}$ in size, was captured on the nitrocellulose filter paper, whereas particles of $>5 \mu \mathrm{m}$ were deposited into a rubber pot at the base of the cyclone. The cyclone was run for 3 minutes in each zone; thus, dust from $5.7 \mathrm{~L}$ of air was sampled from the BZ and $5.7 \mathrm{~L}$ from the SZ. As four replicate stables were sampled per barn, a total of $23 \mathrm{~L}$ of air was sampled for ARD in the SZ and $23 \mathrm{~L}$ in the BZ.

\subsection{Dust Enumeration Procedure}

Postsampling cassettes were transported back to the laboratory where the nitrocellulose membrane filter papers were mounted onto microscope slides and fixed in 5 drops of triacetate. Slides were stored in a dust-free incubator and left for a minimum of 3 days so that the filter paper could dissolve and counting could be done. Airborne respirable dust was counted at $\times 40$ magnification using a standard laboratory binocular microscope using the procedure detailed by Moore-Colyer [24].

\subsection{Data Analyses}

Difference in ARD/L of air between management regimes was determined using split-plot analysis of variance (ANOVA) with whole plots being barn type (2), and subplots being region (2), treatment effects being management regime ( 4 ), replicates ( 8 ) thus $n=128$. Differences between means were calculated using least significant difference test where $\mathrm{LSD}=\mathrm{t}($ error df $) \times$ s.e.d. Because of the skewing of the data, ANOVA was performed on $\log _{10}$ transformed data [25] as per the accepted procedure for right-handed skewed data. Results were expressed as geometric ARD/L air as this value approximates closely to the median which is the most accurate expression of the distribution of the ARD [26,27].

Wilcoxon matched-pairs test was then used to determine the impact of different management regime on ARD in the SZ versus BZ within stable type.

\section{Results}

The average ARD concentrations for both ABs and single stables for the SZ were found for shavings and steamed hay at $301 \pm 103$ and for the BZ were $325 \pm 82$ ARD/L of air. Shavings plus dry hay produced $515 \pm 61$ (SZ) and $731 \pm$ 243 (BZ)/L air, whereas straw plus haylage produced 1,941 $\pm 2,254$ (SZ) and $524 \pm 57$ ARD/L of air. Straw plus dry hay produced the most ARD/L of air at 3,088 $\pm 3,892(\mathrm{SZ})$ and $2,849 \pm 3,751$ (BZ). When averaged across both SZ and BZ and $A B$ and single stables (Table 1), the management regime of shavings plus steamed hay produced significantly less ARD/L of air compared with shavings and dry hay which was significantly lower than straw and haylage which in turn was significantly lower than straw and dry hay.

Wilcoxon matched pairs test (Table 2) showed that across both $\mathrm{AB}$ and straight stables, there was no difference in ARD/L air between the SZ and BZ when horses were bedded on shavings and fed steamed hay or when bedded on straw and fed dry hay. When the ARD was averaged across both stable types and zones, the straw and dry hay regime produced more than 10 times the ARD/L air (313 vs. 3,793 ) compared with the shavings and steamed hay. Dry hay and shavings produced significantly more ARD/L air in the BZ compared with SZ in straight stables, but not in ABs, whereas straw bedding and haylage produced the opposite with ARD/L air being significantly higher in the SZ compared with BZ in both stable types.

\section{Discussion}

This is the first study to document ARD in stables where horses were fed steamed hay as part of the daily management regime. Results from this study clearly demonstrate that different forage and bedding types have major impacts on ARD concentrations in horse stabling. Steamed hay and shavings produced the lowest level of ARD and the lowest variability of dust levels across both zones and stable types and thus is the preferred management regime for reducing

Table 1

Geometric mean airborne respirable dust (ARD) levels per liter of air from the breathing zone and stable zone from eight American barns and eight single stables under four different management regimes.

\begin{tabular}{lllll}
\hline Management Regime & $\begin{array}{l}\text { Shavings and } \\
\text { Steamed Hay }\end{array}$ & $\begin{array}{l}\text { Shavings and } \\
\text { Dry Hay }\end{array}$ & Straw and Haylage & $\begin{array}{l}\text { Straw and } \\
\text { Dry Hay }\end{array}$ \\
\hline Log ARD/L air & $2.474^{\mathrm{a}}$ & $2.775^{\mathrm{b}}$ & $2.928^{\mathrm{c}}$ & $3.351^{\mathrm{d}}$ \\
\hline
\end{tabular}

${ }^{\mathrm{abcd}}$ Values in the same row not sharing common superscripts differ significantly $(P<.05)$. 
Table 2

Airborne respirable dust (ARD) content/L of air in the breathing zone (BZ) and general stable zone (SZ) measured in American Barn and single stables when subjected to four different management regimes.

\begin{tabular}{|c|c|c|c|c|c|c|}
\hline \multirow[t]{2}{*}{ Management Regime } & \multicolumn{3}{|c|}{ American Barn } & \multicolumn{3}{|c|}{ Single Stables } \\
\hline & SZ & $\mathrm{BZ}$ & Sig & $\mathrm{SZ}$ & $\mathrm{BZ}$ & Sig \\
\hline Steamed hay + shavings & 325 & 300 & 1.00 & 270 & 360 & 0.219 \\
\hline Dry hay + shavings & 522 & 827 & 0.083 & 509 & 637 & 0.021 \\
\hline Haylage + straw & 972 & 517 & 0.001 & 2,912 & 533 & 0.001 \\
\hline Dry hay + straw & 6,250 & 5,079 & 0.382 & 2,901 & 943 & 0.234 \\
\hline
\end{tabular}

ARD/L air for horses stabled either in ABs or in single stables.

The high variability between replicate samples for the high dust-producing regimes of straw + haylage and straw + dry hay as denoted by the high standard deviations can be attributed to different ventilation rates, straw and forage quality, and feeding method, as some horses were fed from the ground and others from hay nets or chest-height mangers. Horses on the steamed hay and shavings regime were also fed a variety of ways but as previous work has shown $[24,25]$ steaming consistently reduces ARD levels by $99 \%$ from hay regardless of contamination level. Moreover, dust-extracted shavings are also uniformly low dust thus less dust will be released into the environment from the forage and bedding so a cleaner environment is ensured if these materials are used.

Although all samples were taken during quiet periods in the daily regime, samples were taken over a period of 1 month from November to December in 2013 and weather conditions such as temperature, humidity, and wind speed varied. However, samples from each management regime and stable type were taken randomly throughout this period with several different systems sampled each session; thus, weather conditions were not correlated with stable type or management regime. Data was collected in the present experiment in the UK winter when wind speed is generally higher than in the summer. Witkowska et al [28] found season had a major impact on ARD in an AB system with levels higher in summer than winter. Thus, it is likely that dust levels in all stables would increase in the summer making the choice of bedding and forage even more critical in the active competition season.

These results are comparable with earlier findings $[29,30]$ that reported significantly lower average ARP in the general stables where horses were fed low-dust forage, that is, haylage or silage and bedded on wood shavings compared with stables where horses were fed dry hay and bedded on straw. Clements and Pirie [19] also reported significant reductions in average ARD levels in the BZ of a pony fed soaked or immersed hay compared with dry hay. Although it is likely that using a low-dust regime such as feeding haylage and bedding on shavings would have similar benefits in terms of ARD to steamed hay and shavings, many owners do not have sufficient horses to use haylage within the recommended shelf life and find that it can be too energy dense for their horses in light work. Hay is therefore often the forage of choice.

Although ARD levels in the SZ and BZ in this experiment were influenced by bedding and forage, respectively, generally using straw as a bedding material put more ARD into the whole stable compared with using dusty forage and this dust permeated the BZs of all the individual horses. This is in agreement with previously reported findings [14,31] reporting that straw produced significantly more ARD in the general SZ than when shavings were used as bedding. However, bedding on shavings and feeding dry hay not only put more ARD into the BZ but also raised ARD levels in general SZ compared with the shavings and steamed hay regime. Feeding haylage and bedding on straw produced significantly higher $(P<.008)$ levels of ARD in the $\mathrm{SZ}$ of both $\mathrm{ABs}$ and single stable types compared with the BZ. However, the same regime produced significantly $(P<$ .04) more ARD in the SZ in single boxes compared with ABs stables indicating lower clearance levels possibly due to low ventilation rate or restricted air space in single stables compared with ABs. Breathing zone dust was also raised by approximately $200 \mathrm{ARD} / \mathrm{L}$ air compared with the shavings and steamed hay.

Clements and Pirie [19] reported that putting just one stable in a row in an $A B$ system on a low-dust regime can significantly lower ARD levels across the barn. The results from this experiment also suggest that shared airspace is influenced by management regime in adjacent boxes, as when considering ARD levels across both zones, horses fed dry hay and bedded on straw in ABs were breathing in significantly more ARD/L of air $(5,664)$ compared with horses on the same regime in single boxes $(1,922 \mathrm{ARD} / \mathrm{L}$ of air). Cross-contamination is thus a potential issue in livery yards where individual owners employ different management regimes for their horses.

General sweeping, grooming or shaking straw, and shavings were not standardized in this experiment; however, samples were taken during quite times in all the stables; thus, no direct creation of dust contaminated the samples. However, Lacey [21] indicated that once dust is air born, ARD particles of $5 \mu \mathrm{m}$ or less obey Stokes Law and unless removed by ventilation stay in the atmosphere for very long periods. Thus, some of the ARD captured by the cyclone sampler could have been a result of stable management activities that morning. However, these results still show the levels of ARD horses are exposed to in different stable types and give a real-life measurement of the impact of management regime on ARD in the stable environment.

\section{Conclusion}

Results from this experiment clearly show that feeding steamed hay and bedding horses on shavings produces the lowest level of ARD of the four regimes tested here and is 
thus the preferred regime whether used in ABs or single stables. Feeding low-dust forage or using low-dust bedding will only partially reduce the ARD in the stable environment and cannot be recommended as a management regime for performance horses. Dry hay and straw produced a very dusty environment in both stable types, but the effect is magnified when horses have a common airspace as in an AB. Dry hay and bedding on straw cannot be recommended as a suitable management system for any stabled horse but is particularly hazardous for those animals kept in ABs.

\section{References}

[1] Couetil LL, Cardwell JM, Gerber V, Lavoie JP, Leguillette R, Richard E. Inflammatory airway disease of horses-revised consensus statement. J Vet Intern Med 2016;30:503-15.

[2] Holcombe SJ, Jackson C, Gerber V, Jefcoat A, Berney C, Eberhardt S, et al. Stabling is associated with airway inflammation in young Arabian horses. Equine Vet J 2001;33:244-9.

[3] Vandenput S, Votion D, Duvivier DH, van Erke E, Anciaux N, Art T, et al. Effect of set stable environmental control on pulmonary function and airway reactivity of COPD affected horses. Vet J 1998; 155:189-95.

[4] McPherson E, Thomas J. Chronic obstructive pulmonary disease in the horse. Equine Vet J 1983;13:167-70.

[5] Clarke A, Madelin TM, Altpress RG. The relationship of air hygiene in stables to lower airway disease and pharyngeal lymphoid hyperplasia in tow groups of Thoroughbred horses. Equine Vet J 1987;19: 524-30.

[6] Leadon DP. Air hygiene in stables. Ir Vet J 1986;40:90-2.

[7] Pirrone F, Albertini M, Clement MG, Lafortuna CL. Respiratory mechanics in Standardbred horses with subclinical inflammatory airway disease and poor athletic performance. Vet J 2007;173:144-50.

[8] Couetil LL, Hoffman AM, Hodgson J, Buechner-Maxwell V, Viel L, Wood JNN, Lavoie JP. Inflammatory airway disease of horses. J Vet Intern Med 2007;21:356-61.

[9] Pearson CC, Sharples TJ. Airborne dust concentrations in livestock buildings and the effect of feed. J Agr Eng Res 1995;60: $145-54$.

[10] Burrell MH, Wood JL, Whitwell KE, Chanter N, Mackintosh ME, Mumford JA. Respiratory disease in Thoroughbred horses in training: the relationship between disease and viruses, bacteria and environment. Vet Rec 1996;139:308-13.

[11] Clements JM, Pirie RS. Respirable dust concentrations in equine stables. Part 2: the benefits of soaking hay and optimising the environment in a neighbouring stable. Res Vet Sci 2007;83:263-8.

[12] Debilquy P, Nicks B, Canart B, Buzitu S, Dewaele A. Animal activity and dust. Ann Med Vet J 1991;135:215-20.

[13] Art T, McGorum BC, Lekeux P. Environmental control of respiratory disease. In: Lekeux P, editor. Equine respiratory disease. 1st ed. Ithaca: New York, USA: International Veterinary Information Service; 2002.
[14] Mills D, Clarke A. Housing, management and welfare. In: Waren N, editor. Welfare of horses. Springer, Netherlands: Kluwer Academic Publishers; 2002. p. 77-97.

[15] Curtis L, Raymond S, Clarke A. Dust and ammonia in horse stalls with different ventilation rates and bedding. Aerobiology 1996;12: 239-47.

[16] Deacon J. The microbial world: airborne microorganisms. Edinburgh: University of Edinburgh, http://archive.bio.ed.ac.uk/jdeacon/microbes/ airborne.htm; 2016.

[17] May ML, Derksen FJ, Berthold B, Holcobe SJ, Robinson E. Air quality in stables at an American Thoroughbred racetrack. AAEP Proc 2007 53:77-80.

[18] Hessel EF, Garlipp F, Herman FA, Van den Weghe I. Generation of airborne particles from horse feeds depending on processing and type. J Equine Vet Sci 2009;29:665-74.

[19] Clements JM, Pirie RS. Respirable dust concentrations in equine stables. Part 1: validation of equipment and effect of various management systems. Res Vet Sci 2007;83:256-62.

[20] Ivester KM, Couetil LL, Moore GE, et al. Environmental exposures and airway inflammation in young thoroughbred horses. J Vet Intern Med 2014;28:918-24.

[21] Lacey J. Aerobiology and health: the role of airborne fungal spores in respiratory disease. In: Hawksworth DL, editor. Frontiers in mycology. Wallingford, Oxfordshire: CAB International; 1990.

[22] Jones R, McGreevy PD, Robertson A, Clarke AF, Wathes CM. Survey of the designs of racehorse stables in the southwest of England. Equine Vet J 1987;19:454-7.

[23] Ivester KM, Smith K, Moore GE, Zimmerman NJ, Couetil LL. Variability in particulate concentrations in a horse training barn over time. Equine Vet J 2012;44:51-6.

[24] Moore-Colyer MJS. The effects of soaking hay fodder for horses on dust and mineral content. Anim Sci 1996;63:337-42.

[25] Moore-Colyer MJS, Taylor J, James R. The effect of steaming and soaking on the respirable particle, bacteria, mould and nutrient content in hay for horses. J Equine Vet Sci 2016;39:62-8.

[26] Moore-Colyer MJS, Lumbis K, Longland AC, Harris PA. The effect of five different wetting treatments on the nutrient content and microbial concentration in hay for horses. PLoS One 2014;9: e114079.

[27] Petri A, Watson P. Statistics for veterinary and animal science. London UK: Blackwell Science; 1999.

[28] Witkowska D, Keiatkowska-Stenzel A, Jozwiak A, Chorazy L, Wojeil A. Microbiological contamination of air inside and around stables during different seasons of the year. Pol J Environ Stud 2012; 21:1061-6.

[29] McGorum BC, Ellison J, Cullen RT. Total and respiratory airborne dust and endotoxin concentrations in three equine management systems. Equine Vet J 1998;30:430-4.

[30] Woods PSA, Robinson NE, Swanson MC, Reed CE, Broadstone R, Derksen V. Airborne dust and aeroallergen concentration in a horse stable under two different management systems. Equine Vet J 1993; 25:208-13.

[31] Tanner MK, Swinker AM, Beard ML, Cosma GN, Traub-Dargatz JL, Martinez AB, Olenchock SA. Effect of phone book paper versus sawdust and straw bedding on the presence of airborne gramnegative bacteria, fungi and endotoxin in horse stalls. J Equine Vet Sci 1998;18:457-61. 